\title{
Recurrent Hepatoblastoma
}

National Cancer Institute

\section{Source}

National Cancer Institute. Recurrent Hepatoblastoma. NCI Thesaurus. Code C8643.

The reemergence of hepatoblastoma after a period of remission. 